\title{
Serum anti-thyroid peroxidase antibody in infertile Nepalese women: a hospital-based study
}

\author{
Eans Tara Tuladhar ${ }^{1}$, Sujina Manandhar ${ }^{1}$, Mithileshwor Raut ${ }^{1}$, Aseem Bhattarai ${ }^{1}$, \\ Vijay Kumar Sharma ${ }^{1}$, Binod Kumar Yadav ${ }^{1}$ \\ ${ }^{I}$ Department of Biochemistry, Tribhuvan University Teaching Hospital, Kathmandu, Nepal
}

\section{Keywords: \\ Anti-thyroid peroxidase; Autoimmune; Infertility; Thyroid disease;}

\begin{abstract}
Background: Infertility is a critical component of reproductive health that can precipitate agony for a couple. Antibodies against thyroid peroxidase can lead to not only autoimmune thyroiditis which is highly prevalent in women, but may also represent a generalized autoimmune milieu in our body that can be associated with infertility. This study aims to assess anti-thyroid peroxidase antibodies in female patients with infertility.
\end{abstract}

Materials and Methods: This is a cross-sectional study carried out in the Department of Biochemistry, Tribhuvan University Teaching Hospital over three months (November 2018 to January 2019). All women undergoing work up at the infertility clinic with reported normal thyroid function and otherwise normal levels of reproductive hormones were recruited for this study. Anti-thyroid peroxidase levels were estimated in their serum samples by enzyme-linked immunosorbent assay.

Results: Of the eighty-seven females that were selected for the study, 54 were infertile females, 16 were pregnant women in their first trimester and 17 were non-pregnant females in their reproductive age. Four positive cases of anti-thyroid peroxidase were detected among infertile females ( $7.4 \%$ within the group), 2 amid non-pregnant females (11.76\% within-group) while no positive cases were detected within the pregnant group. However, the occurrence was not statistically significant $(\mathrm{p}=0.4)$. The pregnant group showed higher mean anti-thyroid peroxidase levels compared to both infertile and non-pregnant females though statistical significance could not be established $(\mathrm{p}=0.066)$.

Conclusion: Functional autoimmune antibodies, like anti-thyroid peroxidase levels, do not have a significant primary association with infertility.

\section{Correspondence:}

Dr. Eans Tara Tuladhar,

Department of Biochemistry,

Maharajgunj Medical Campus, Tribhuvan University Teaching Hospital,

Kathmandu, Nepal

ORCID ID: 0000-0001-5705-3953

Email: eanstara@gmail.com

Reveived : July $20^{\text {th }} 2020$; Accepted : September $26^{\text {th }} 2020$

Citation: Tuladhar ET, Manandhar S, Raut M, Bhattarai A, Sharma, VK, Yadav BK. Serum antithyroid peroxidase antibody in infertile Nepalese women: a hospital-based study. J Pathol Nep 2020;10:1742-5. DOI 10.3126/jpn.v10i2.27267

Copyright: This is an open-access article distributed under the terms of the Creative Commons Attribution 4.0 International License, which permits unrestricted use, distribution, and reproduction in any medium, provided the original author and source are credited.

\section{INTRODUCTION}

Infertility is a disease of the reproductive system defined by the failure to achieve a clinical pregnancy after 12 months or more of regular unprotected sexual intercourse .$^{1}$ Globally, infertility affects approximately $10-15 \%$ of couples. ${ }^{2}$ According to a global survey report conducted in 2010 , Nepal showed a prevalence of primary infertility at $1.9 \%$ and secondary infertility at $7.9 \% .^{3}$, done by Subedi et al in the eastern region of Nepal, showed an incidence of infertility cases as $5.45 \%$ which was dominated by secondary infertility and malefactor. The incidence of primary infertility cases was $1.7 \%{ }^{4}$ 
Over the last decade, thyroid screening has been a routine procedure in all pregnant and infertile females. Among thyroid disorders and autoimmune diseases, thyroid autoimmunity is the most prevalent autoimmune condition affecting up to $5-20 \%$ of women in the reproductive life phase. ${ }^{5}$ Thyroid autoimmunity may present with or without clinical or subclinical thyroid dysfunction. It has been associated with endometriosis, polycystic ovarian disease (PCOD), and premature ovarian failure cause of infertility. ${ }^{5,6}$ Anti-thyroid peroxidase (anti-TPO) level is investigated only in clinical or subclinical thyroid disorder. Anti-TPO antibodies represent a generalized autoimmune milieu in our body. ${ }^{7}$ The prevalence of anti-TPO antibodies have been observed to be significantly higher among infertile women as compared to the healthy, fertile women of the same age group. ${ }^{7-9}$

This study was done to compare the status of anti -TPO antibodies between infertile females who were undergoing workup for conceiving against the values in the pregnant females in their first trimester (unassisted pregnancy) and also with the values seen in non-pregnant reproductive age group females with at least parity one to see the primary role of anti-TPO in the achievement of medical pregnancy.

\section{MATERIALS AND METHODS}

This was a cross-sectional observational study carried out in the Department of Biochemistry at Tribhuvan University Teaching Hospital over three months from November 2018 to January 2019. All infertile women undergoing work up in the infertility clinic between the age group of 20 to 45 years were recruited in the infertile female (IF) group. The thyroid and other reproductive hormones of these patients were within the normal range. Ultrasonography of these participants had ruled out polycystic ovarian disease (PCOD) and endometriosis. The malefactor was ruled out to recruit the cases. Age-matched pregnant females (PG) in the first trimester and non-pregnant females (NP) in the reproductive age, having at least one child, were chosen as controls. The controls were recruited from the obstetric outpatient department and general health clinic respectively.
Ethical clearance was obtained from the Institutional Review Board and written consent was taken from the candidates. For the analysis, a $3 \mathrm{ml}$ blood sample was collected from all the participants, the serum was separated and antiTPO antibodies were analyzed following the protocol of Euroimmu anti-TPO enzyme-linked immunosorbent assay (ELISA) kit. The anti-TPO values above $50 \mathrm{IU} / \mathrm{ml}$ were taken as positive as per the instruction manual. Descriptive and statistical analysis was done by SPSS version 17 . Oneway ANOVA was carried out to compare the mean antiTPO values between the three groups and Fisher's exact test was used to compare the occurrence of positive cases among these groups.

\section{RESULTS}

During the study period, 87 females were enrolled in the study. This consisted of 54 cases in the IF group, with a mean age of $27.17 \pm 4.12$ years. There were 16 cases in the PG group with the mean age of $26.79 \pm 4.14$ years, and 17 participants NP group with the mean age of $26.38 \pm$ 4.61years.

In total, there were 6 anti-TPO positive cases. This value accounted for $6.9 \%$ of the whole study population. Four positive cases of anti-TPO were detected in the IF group (7.4\% within the IF group), 2 in the NP group $(11.76 \%$ within the NP group) while no positive cases were detected in the PG group. Fisher's exact test showed the occurrence of positive cases in different groups to be insignificant $(p=0.4)$. The anti-TPO values of the positive cases were winsorized and the results obtained are given in table 1 . The mean anti-TPO was higher in pregnant females than in the other two groups. However, the statistical significance of this mean difference could not be established $(p=0.066)$.

\section{DISCUSSION}

To be able to conceive is a desire of any couple in a marital relationship and infertility can lead to not only distress and depression but also discrimination and ostracism. ${ }^{3}$ We found the mean age at which couples seek treatment is $27.25 \pm$

Table 1: Comparison of anti-TPO among infertile group, pregnant control group, and non-pregnant control group

\begin{tabular}{|c|c|c|c|c|}
\hline & Infertile cases $(n=54)$ & Pregnant control $(n=15)$ & Non-pregnant control $(n=17)$ & P-Value \\
\hline $\begin{array}{l}\text { Age in years } \\
\text { (Mean Standard deviation) }\end{array}$ & $27.17 \pm 4.12$ & $26.79 \pm 4.14$ & $26.38 \pm 4.61$ & \\
\hline $\begin{array}{l}\text { Anti TPO (IU/ml) } \\
\text { (Mean Standard deviation) }\end{array}$ & $5.36 \pm 3.14$ & $7.56 \pm 2.57$ & $6.30 \pm 4.18$ & $\mathrm{p}=0.066$ \\
\hline Range & 0.60 to 12.89 & 3.7 to 12.26 & 0.83 to 19.6 & \\
\hline $95 \%$ confidence interval & $4.45-6.2$ & $6.19-8.9$ & $3.99-8.62$ & \\
\hline Positive Cases & $4(7.4 \%)$ & - & $2(11.76 \%)$ & \\
\hline $\begin{array}{l}\text { Serum Anti TPO concentra- } \\
\text { tion in psitive cases }\end{array}$ & $\begin{array}{l}243.9 \mathrm{IU} / \mathrm{ml} \\
356.2 \mathrm{IU} / \mathrm{ml} \\
443.7 \mathrm{IU} / \mathrm{ml} \\
520.7 \mathrm{IU} / \mathrm{ml}\end{array}$ & - & $\begin{array}{l}197.8 \mathrm{IU} / \mathrm{ml} \\
422.6 \mathrm{IU} / \mathrm{ml}\end{array}$ & \\
\hline
\end{tabular}


4.12 years, similar to reports from other researchers. ${ }^{4,10}$ This mean age is also near to the documented global mean age of childbearing since 1970.3 In the age below 20 years and above 45 years, fewer couples are seeking a child. ${ }^{3}$

In the IF group, the occurrence of anti-TPO positive cases was only $7.4 \%$ which is less than other studies. ${ }^{5-9}$ These studies showed elevated anti-TPO values in infertile females suffering from PCOD and endometriosis. The current study excluded the females with a diagnosis of PCOD and endometriosis, which might be the reason for the low occurrence of positive cases.

This study did not find elevated anti-TPO in the PG group although various literature shows prevalence ranging from 4 to $19 \% .^{7,11}$ This might be due to the small sample size which is the major limitation in this study. However, we detected a higher occurrence of anti-TPO cases in the general nonpregnant female population in the reproductive age group (11.76\% within group NP). In total, elevated anti-TPO cases consisted of $6.9 \%$, which lies within the reported prevalence of elevated anti-TPO cases (5-24\%) in the general female population..$^{5,12,13}$

This study did not find any significant difference in the occurrence of elevated anti-TPO between IF and NP group, as shown by Pompe et al which again could be the result of the exclusion of the infertility cases associated with endometriosis and PCOD. ${ }^{9}$

The same literature that shows a higher prevalence of infertility associated with higher anti-TPO levels have also concluded that the elevated anti-TPO levels alone do not reduce the chance of pregnancy. ${ }^{7.8}$ Instead, studies have shown elevated anti-TPO value to be associated with miscarriage or preterm delivery, highlighting its role in healthy and sustained implantation ${ }^{7,9,11,14}$ As indicated by literature, altered anti-TPO does not have a role in fertilization and implantation. This is also highlighted in our study, as we did not find any significant difference in the anti-TPO values between IF and PG groups. Since we did not follow up on the outcome of assisted pregnancy in anti-TPO positive infertile females and our PG control were in the first trimester of pregnancy, we could not comment on the outcome of pregnancy. Thus, although our study has a lower occurrence of elevated anti-TPO cases in the IF group and a small sample size of the PG group, our result is similar to the literature confirming elevated anti-TPO not to be associated with infertility due to implantation failure.

The mean anti-TPO levels between the three groups were compared. Even with a limited sample size, we found a higher trend of mean anti-TPO level in pregnant control in the first trimester among the three groups which was also seen in the study by Meena et al. ${ }^{7}$ This might be the result of the altered physiological status of pregnancy.

\section{CONCLUSIONS}

Functional autoimmune antibodies, like anti-TPO, does not have a significant primary association with infertility.

\section{Limitations of The Study}

The sample size is the main limitation of the study as the study period was short. This is a hospital-based study, so it may not represent the whole population of the country. Finally, the outcome of the assisted pregnancy in infertile patients was not followed.

\section{Acknowledgement}

The research team would like to acknowledge Mr. Diwas Shrestha for his help in carrying out this research. We would also like to acknowledge Prof. Dr. Bekha Laxmi Manandhar, Prof. Dr. Josie Baral, Mrs. Laxmi Mahat, and the infertility clinic team for their help in recruiting the participants.

\section{Conflict of Interest: None}

\section{REFERENCES}

1. World Health Organization. Sexual and reproductive health [Internet]. World Health Organization; 2019. Website

2. Fritz MA, Speroff L. Clinical gynecologic endocrinology and infertility [Internet]. Philadelphia: Wolters Kluwer Health/Lippincott Williams \& Wilkins; 2011. Website

3. Mascarenhas MN, Flaxman SR, Boerma T, Vanderpoel S, Stevens GA. National, Regional, and Global Trends in Infertility Prevalence Since 1990: A Systematic Analysis of 277 Health Surveys. PLoS Med 2012;9. Crossref

4. Subedi S, Lamichhane S, Chhetry M. Study of Infertile Couples Attending a Teaching Hospital in Eastern Nepal. J Nepal Med Assoc 2016;55:22-5. Crossref

5. Artini PG, Uccelli A, Papini F et al. Infertility and pregnancy loss in euthyroid women with thyroid autoimmunity. Gynecol Endocrinol 2013;29:36-41. Crossref

6. Wang X, Ding X, Xiao X, Xiong F, Fang R. An exploration on the influence of positive simple thyroid peroxidase antibody on female infertility. Exp Ther Med 2018;16:3077-81. Crossref

7. Meena M. The Effect of Anti-Thyroid Peroxidase Antibodies on Pregnancy Outcomes in Euthyroid Women. J Clin DIAGNOSTIC Res. 2016;10. Crossref

8. Grassi G, Balsamo A, Ansaldi C, Balbo A, Massobrio M, Benedetto C. Thyroid autoimmunity and infertility. Gynecol Endocrinol 2001;15(5):389-96. Crossref

9. Poppe K, Glinoer D, Tournaye H et al. Thyroid autoimmunity and female infertility. Verhandelingen - Koninklijke Academie voor Geneeskunde van België 2006;68: 357-77. Website

10. Tamrakar SR, Bastakoti R. Determinants of Infertility in Couples. J Nepal Health Res Counc $2019 ; 17: 85-9$. Crossref

11. Rajput R, Yadav T, Seth S, Nanda S. Prevalence of thyroid peroxidase antibody and pregnancy outcome in euthyroid autoimmune positive pregnant women from a tertiary care center in Haryana. Indian J Endocrinol Metab 2017;21:577-80. $\underline{\text { Crossref }}$ 
12. Amouzegar A, Gharibzadeh S, Kazemian E, Mehran L, Tohidi M, Azizi F. The Prevalence, Incidence and Natural Course of Positive Antithyroperoxidase Antibodies in a Population-Based Study: Tehran Thyroid Study. Portolés M, editor. PLoS One. 2017;12:e0169283. Crossref

13. Medici M, Porcu E, Pistis G et al. Identification of Novel Genetic Loci Associated with Thyroid Peroxidase Antibodies and Clinical Thyroid Disease. Cotsapas C, editor. PLoS Genet. 2014;10: e1004123. Website
14. Lata K, Dutta P, Sridhar S et al. Thyroid autoimmunity and obstetric outcomes in women with recurrent miscarriage: a case-control study. Endocr Connect 2013;2:118-24. Crossref 